Autori:

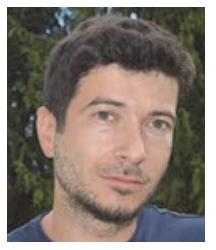

Matej Kušar, dipl.ing.grad.

University of Ljubljana

Faculty of Civil and Geodetic Engineering matej.kusar@gi-zrmk.si

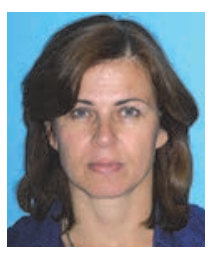

Assoc.Prof. Jana Šelih, PhD. CE

University of Ljubljana

Faculty of Civil and Geodetic Engineering jana.selih@fgg.uni-lj.si

\section{Analysis of bridge condition on state network in Slovenia}

Matej Kušar, Jana Šelih

\title{
Analysis of bridge condition on state network in Slovenia
}

During operation, bridge condition is decreasingdue to various effects. The condition is described by "condition rating coefficient", determined by visual assessment. Condition of Slovenian state road bridge network is analyzed. The condition rating database is structured with respect to traffic load, climate zone, structural material, structural type and bridge element. Changes of condition rating coefficient with time are presented and analyzed. Results show that climate and exposure to water are the most important parameters influencing the condition of bridges. Challenges related to assessment methodology are identified and discussed.

Key words:

bridges, condition rating, state road network, maintenance

Znanstveni rad - Prethodno priopćenje

Matej Kušar, Jana Šelih

\section{Analiza stanja mostova na državnim cestama u Sloveniji}

Stanje mostova neprestano mijenja se zbog različitih utjecaja, a opisuje se "koeficijentom vrednovanja stanja" koji se određuje na osnovu vizualnih pregleda. U radu je analizirano stanje mostova na slovenskim državnim cestama. Baza podataka koja se temelji na koeficijentu u obzir uzima prometno opterećenje, klimatske zone, konstrukcijske materijale, tip konstrukcije i elemente mosta. U obzir su uzete i promjene koeficijenta tijekom vremena. Rezultati analize pokazuju da su klimatski uvjeti i izloženost utjecajima vode i vlage najutjecajniji parametri koji utječu na stanje mostova. U radu su identificirani i izazovi povezani s metodologijom procjene stanja mostova, a provedena je i diskusija.

Ključne riječi:

mostovi, ocjena stanja, mreža državnih cesta, održavanje

Wissenschaftliche Arbeit - Vorherige Mitteilung

Matej Kušar, Jana Šelih

\section{Analyse des Brückenzustandes im staatlichen Straßennetz Sloweniens}

Im Betriebsverlauf wird der Zustand von Brücken durch verschiedene Einflüsse beeinträchtigt. Meist wird die Lage durch Zustandsbewertungs-Koeffizienten beschrieben, die aufgrund visueller Begutachtung ermittelt werden. Der Zustand des slowenischen Netzwerkes von Straßenbrücken ist in dieser Arbeit analysiert. Dazu ist die Datenbank zur Zustandsbewertung in Bezug auf Verkehrslasten, Klimazonen, Baumateriale, Tragkonstruktionen und Brückenelemente strukturiert worden. Zeitliche Veränderungen der ZustandsbewertungsKoeffizienten sind dargestellt und analysiert. Die Resultate zeigen, dass Wetter- und Wassereinflüsse den Brückenzustand am bedeutsamsten beeinträchtigen. Überdies sind Herausforderungen bezüglich der Bewertungsmethodologie identifiziert und erläutert. 


\section{Introduction}

The road infrastructure is an extremely important part of the existing publicly owned assets. It eases mobility of citizens, enables transport of goods, and contributes to the economic growth and social development. A special attention has to be devoted to its life cycle management: planning, design, construction, maintenance and rehabilitation, and, if justified, demolition and replacement [1, 2].

During their operation and use, the performance of structures is decreasing due to various deterioration processes: inherent ageing and deterioration phenomena triggered by environmental influences, increased traffic load, and possible natural hazards, such as earthquakes, floods, and landslides [2, 3]. The structural design work conducted at the initial stage of design, even when carried out in accordance with the state-of-the-art standards and guidelines, cannot protect the structure from deterioration during the operation stage [3]. Appropriate maintenance and rehabilitation actions need to be planned and implemented throughout the lifecycle of the structure in order to maintain its adequate performance [4].

Rehabilitation actions should be initiated when performance of a structure falls below a pre-defined acceptable level [5]. The scope and type of these actions should be based on the current status of the structure, on the trends identified in recent past, as well as on predictions of the type and rate of future deterioration. Bridges are an important component of the road network, mostly because of capital investment associated with such structures. That is why a clear, well defined, and comprehensive methodology is needed to assess bridge condition during inspections. Only in that case it can be expected that the condition rating will yield meaningful results, i.e. the results that can lead to rational decisions on the priority and scope of refurbishment projects [6].

Considering that costs of maintenance and repair should be kept within a limited budget $[2,7,8]$, most developed countries have prescribed a regular routine condition assessment for bridges at predefined time intervals by using adequate methodologies [6, 9-11]. The majority of the existing bridge maintenance systems (BMSs) are primarily based on information obtained through visual inspections [12]. Even so, the documented ongoing experience reveals that this type of inspection is often unreliable; however, due to its simplicity and cost effectiveness, it should remain the main aid for collecting data [11].

In Slovenia, the first bridge assessment methodology based on visual inspection was established in 1990 [9] and, over the ensuing several years, selective upgrades were made to meet user requirements. After 1993, there was no further development and revision of this methodology, despite the fact that experts and officials representing the road management companies have repeatedly pointed to the need for further improvement. In addition, there is a growing need to establish a comprehensive bridge management system, in which the condition assessment methodology plays an important role [13]. Both of these two activities should be based on systematic analysis of the current condition of bridges, and its expected changes over time.
Consequently, the purpose of the present research is to identify parameters that influence the deterioration rate of bridges, and to structure the existing Slovenian bridge network database according to these parameters. Available data describing the condition of structures within the selected bridge network (measured by the bridge condition rating coefficient) for the past twenty years will therefore be analysed for structural parts (e.g. abutments) and non-structural parts (e.g. wing walls) of the bridge with respect to afore-mentioned parameters. The bridge equipment (e.g. barriers, lighting, expansion joints, etc.) will not be analysed. Based on the obtained results, the main potential shortcomings related to the assessment methodology will be systematically identified.

Three levels of road networks, i.e. highways, state roads, and community roads, are distinguished by legislation [14] in the territory of Slovenia. The present research is limited to structures situated within the state road network.

\section{Inventory and condition assessment methodology}

\subsection{Identification of parameters of influence}

The first step in the management of bridges situated within the road network under consideration is to create their comprehensive inventory that contains relevant data associated with every individual bridge. Within this context, it has to be acknowledged that state road bridges in Slovenia differ by construction material, bearing structure type, length, number of lanes, and traffic load, and are located in different climate zones. Deterioration mechanisms of materials that influence the performance of structures are strongly dependent on environmental factors, in particular on the ambient temperature, relative humidity, and presence of aggressive elements in air and water [15]. As a consequence, parameters that influence deterioration processes occurring in bridges, and their quantification, were identified and justified in a systematic way. The existing inventory of bridges was then structured with respect to the identified parameters of influence.

From the structural material point of view, the superstructures are constructed of reinforced concrete, steel, stone, or pre-stressed concrete. As only eleven bridges within the state road network are constructed either of wood or as composite bridges, they are not taken into the account in the analysis. The substructure load bearing material is predominantly reinforced concrete, except in the case of stone bridges, where the substructure is also made of stone. Consequently, the indicator that defines the structural material of bridges has the following values;

$M_{i} \in(R C, P C$, Sto, Ste $)$

where $R C, P C$, Sto and Ste denote reinforced concrete, prestressed concrete, stone, and steel bridge superstructures.

Three significantly different climate zones can be differentiated in Slovenia: Alpine, Mediterranean and continental zones. 
They result in the appearance of distinct sets of deterioration processes in structural materials [16], and so the climate is considered to be a relevant parameter of influence;

$C l_{\mathrm{i}} \in(\mathrm{Me}, \mathrm{Co}, \mathrm{Al})$

where $\mathrm{Me}$, Co and $\mathrm{Al}$ denote Mediterranean, Continental and Alpine climates.

Traffic load, as one of the key load types for road bridges, has been identified as the third parameter of influence. The Slovenian technical standard addressing traffic load [17], used by the Slovenian Roads Agency (state road network manager) when condition rating data for bridges under consideration are collected, distinguishes 6 categories of traffic load as a function of the nominal vehicle axial load of $100 \mathrm{kN}$, transmitted by double wheels $(4 \times 25 \mathrm{kN})$ to the pavement surface. For the purpose of the present study, these 6 categories were aggregated into 3: light $(\mathrm{L})$, medium $(\mathrm{M})$ and heavy $(\mathrm{H})$ traffic load [17], depending on the number of passes of nominal axial load of $100 \mathrm{kN}$, namely:

$T_{i} \in(L, M, H)$

Limit values defining $L, M$ and $H$ are presented in Table 1.

Table 1. Traffic load categories (simplified from [17])

\begin{tabular}{|c|c|c|}
\hline \multirow{2}{*}{ Traffic load } & \multicolumn{2}{|c|}{$\begin{array}{c}\text { Number of passes for nominal axial load of } \\
100\end{array}$} \\
\cline { 2 - 3 } & daily & in 20 years \\
\hline Heavy (H) & over 300 & over $2 \times 10^{6}$ \\
\hline Medium (M) & 80 to 300 & $6 \times 10^{5}$ to $2 \times 10^{6}$ \\
\hline Light (L) & under 80 & under $6 \times 10^{5}$ \\
\hline
\end{tabular}

The last parameter of influence on the structure level concerns deterioration processes related to the presence of water. From the point of view of their function, bridges can span water, valleys (where viaducts with several spans are often encountered), or roads (overpasses). The main difference between these structures arises from the fact that foundations, abutments, and wing walls of bridges crossing bodies of water are exposed to deterioration phenomena associated with the presence of water: abrasion, erosion, freezing and thawing, or with the permanently high relative humidity values. Bridge substructures spanning valleys or roads are not in direct contact with water and, consequently, they are not exposed to these deterioration processes. The presence of water influences deterioration processes in the construction materials that are used in various bridge elements [18]. The structural type $(F)$ is therefore added to the list of parameters of influence;

$F_{i} \in(B, P)$

where $B$ and $P$ indicate bridges that span water $(\mathrm{B})$, and bridges that span valleys or roads $(P)$, respectively.
The deterioration rate of structures $(b)$ under consideration can be expressed as a function of the above-identified parameters of influence;

$b_{i}=b_{i}\left(M_{p} C_{i}, T_{i} F_{i}\right)$

Where, as already mentioned, $M_{i}$ indicates the structural material, $\mathrm{Cl}_{i}$ the climate type of the geographic area where the structure $i$ is located, $T_{i}$ the traffic load over the structure, and $F_{i}$ the type of structure $i$.

For the purpose of the analysis, the bridge structure is first divided into structural parts: substructure, superstructure and bridge deck [9]. These parts may be subjected to different environmental factors: bridge deck is subjected to traffic load as well as to various environmental loads causing material deterioration; substructure can be, in case of bridges, exposed to direct contact with water and to various environmental loads depending on the bridge location (e.g. wind carrying salt particles for bridges in coastal areas). The deterioration of these bridge elements may progress at different rates. This is why they have to be assessed and analysed separately. Therefore, the bridge structural part $(B e)$ has been identified as an additional parameter of influence, as follows:

$B e_{i}=\left(S_{\text {sub' }}, S_{\text {sup }}, D\right)$

where $S_{\text {sub }}, S_{\text {sup }}$ and $D$ refer to substructure, superstructure, and deck, respectively. The complete list of parameters of influence, with possible range of values for each of these parameters, is presented in Table 2.

Table 2. Identified parameters of influence and range of values assigned to each parameter

\begin{tabular}{|l|c|l|}
\hline Parameter of influence & Value & Description of the parameter \\
\hline Structural material, M & 4 & $\begin{array}{l}R S \text { (reinforced concrete), PC } \\
\text { (pre-stressed concrete), Sto } \\
\text { (stone), Ste (steel) }\end{array}$ \\
\hline Climate zone, Cl & 3 & $\begin{array}{l}\text { Me (Mediterranean), Co } \\
\text { (Continental), Al (Alpine) }\end{array}$ \\
\hline Traffic load, $T$ & 3 & $\begin{array}{l}L \text { (light), M (medium), H } \\
\text { (heavy) }\end{array}$ \\
\hline Structural type, F & 2 & $\begin{array}{l}B \text { (bridge over water), } P \\
\text { (bridge over valley or road) }\end{array}$ \\
\hline Structural part, Be & 3 & $\begin{array}{l}S_{\text {sub }} \text { (substructure), S } \\
\text { (superstructure), D (deck) }\end{array}$ \\
\hline
\end{tabular}

The present bridge inventory of the Slovenian state road network consists of 1282 bridges [19]. As already mentioned, due to their poor representation, eleven bridges made of either wood or composite material were not included in the analysis. A total of 1271 bridges were therefore taken into the account in the present analysis. 
Table 3. Number of bridges under consideration, structured with respect to the identified parameters of influence

\begin{tabular}{|c|c|c|c|c|c|c|c|c|}
\hline \multirow{2}{*}{$\begin{array}{l}\text { Material } \\
\text { (superstructure) }\end{array}$} & \multirow{2}{*}{$\begin{array}{c}\text { Type of } \\
\text { construction }\end{array}$} & \multirow{2}{*}{$\begin{array}{c}\text { Number } \\
\text { of } \\
\text { structures }\end{array}$} & \multicolumn{3}{|c|}{ Traffic load } & \multicolumn{3}{|c|}{ Climate type } \\
\hline & & & $L$ & $M$ & $H$ & Me & Co & Al \\
\hline \multirow{2}{*}{ Reinforced concrete $(R C)$} & $\mathrm{B}$ & 899 & 538 & 202 & 159 & 81 & 754 & 64 \\
\hline & $\mathrm{P}$ & 150 & 62 & 29 & 59 & 35 & 104 & 11 \\
\hline Stone (Sto) & $\mathrm{B}$ & 97 & 58 & 30 & 9 & 37 & 58 & 2 \\
\hline Pre-stressed concrete $(P C)$ & $\mathrm{B}$ & 75 & 29 & 20 & 26 & 1 & 74 & 0 \\
\hline Steel (Ste) & $\mathrm{B}$ & 50 & 42 & 6 & 2 & 6 & 40 & 4 \\
\hline \multirow{2}{*}{ TOTAL } & & \multirow{2}{*}{1271} & 729 & 287 & 255 & 160 & 1030 & 81 \\
\hline & & & \multicolumn{3}{|c|}{1271} & \multicolumn{3}{|c|}{1271} \\
\hline
\end{tabular}

Table 3 shows that a vast majority of bridges are made of reinforced concrete and are located within the continental climate type. Only a small number of bridges are located in the Alpine climate region, due to large proportion of the mountainous terrain having low density of population and accompanying scarce road infrastructure.

\subsection{Assessment methodology}

The methodology currently in use [10] focusses exclusively on the assessment of the structure's condition at the time of assessment. It is based on the analysis of the damage and possible deficiencies identified visually during the site visit by an experienced assessor. Both can appear on structural or non-structural parts, and they need to be identified and quantified for each element of the bridge. In order to obtain the condition rating for an overall structure, the condition ratings of separate structural elements are summed up. Non-dimensional bridge condition rating, $R$, is then defined as the sum of ratings of separate parts of the structure:

$R=R_{\text {sub }}+R_{\text {sup }}+R_{\text {deck }}$

where $R_{\text {sub' }} R_{\text {sup }}$ and $R_{\text {deck }}$ are the substructure, superstructure and bridge deck ratings, respectively. The listed parts of the structure consist of several elements. The substructure, for example, consists of foundations, abutments, wing walls, and other elements, depending on the type of bridge. Each of these elements can be undamaged, or can exhibit either one or several damage types. The rating for the selected damage type (i) and selected element (j), $R_{i f^{\prime}}$ is determined by means of the following expression;

$R_{i j}=B_{i} \cdot K_{1, j} \cdot K_{2, i, j} \cdot K_{3, i, j j} \cdot K_{4, i, j}$

where $B_{i}$ is the reference assessment value for the identified damage $i(\mathrm{i}=1, \ldots \mathrm{m} ; \mathrm{m}$ is the total number of identified instances of damage), $k_{1, j}(\mathrm{j}=1, \ldots \mathrm{n} ; \mathrm{n}$ is the number of elements of the analysed bridge) the weight indicating the importance of the element $j_{1} K_{2, i, j^{\prime}}$ the weight indicating intensity of damage $i$ on the element $j_{1} K_{3, i, j}$ the weight expressing the extent of the damage $i$ on the element $j$; and $K_{4, i j}$ the weight emphasizing the urgency of intervention on the element $j$ (due to safety, usability, and durability threat originating from damage $\boldsymbol{l}$.

An overall condition rating for the bridge, taking into consideration the condition rating of each individual bridge element of $R_{\text {sub' }} R_{\text {sup }}$ and $R_{\text {deck' }}$ is determined as follows;

$R=\sum_{i=1}^{m} \sum_{j=1}^{n} R_{i, j}=\sum_{i=1}^{m} \sum_{j=1}^{n} B_{i} \cdot K_{1, j} \cdot K_{2, i, j} \cdot K_{3, i, j} \cdot K_{4, i, j}$

The rating values for the substructure, superstructure and bridge deck in Eq. (9), are defined as the sum of condition ratings of their respective elements.

The values of weights $K_{2^{\prime}, j} \in[0,4 ; 1,0], K_{3^{\prime}, j} \in[0,5 ; 1,0]$ and $K_{4^{\prime}, j} \epsilon$ $[1,0 ; 5,0](i=1, \ldots m, j=1, \ldots n)$ are determined by the assessor during the site visit. Conversely, the weights $B_{i} \in[1,0 ; 5,0]$ and $K_{1, j} \in[0,3 ; 1,0]$ depend only on the damage type and bridge element where the damage is located, and are consequently not determined by the assessor. Values of $\mathrm{B}_{i}$ in case of corrosion, for example, range from 1 (e.g. corrosion of stirrups) to 5 (rupture of prestressed cable).

In accordance with the methodology, first remedial works on the bridge are required when the condition rating $\mathrm{R}$ exceeds the value 20 25, depending on importance of the bridge for the network. Threshold values are not prescribed for individual bridge elements. For the purpose of further analysis, the threshold values for the substructure and superstructure were set to 12 and for bridge deck to 8 units. It should be noted that the current assessment methodology does not allow direct translation of the condition rating value into the extent of element damage. If equal condition rating values are recorded for different elements, the bridge deck is considerably more damaged than the substructure and superstructure. In order to analyse the behaviour of structures, the selected threshold values will later be structured into four intervals of equal length that will define deterioration levels.

The assessment of structures within the network under consideration, based on the above described methodology, has been conducted every two years since 1993. Results of up to 10 assessments per structure are therefore available for the analysis. 
However, the condition rating information system has a major weakness that should be addressed in the current analysis: it does not register explicitly if the renovation of a selected bridge has actually been carried out. The conducted renovation should be visible from the recorded condition rating changes over time. In other words, the renovated structure should exhibit a significant increase in the condition rating after renovation.

\section{Data analysis}

The condition rating data, provided by the state road network manager, were analysed for the time period from 1993 to 2011 for a total of 1271 structures. The collected data were sorted based on parameters defined in Table 2. Assessments were performed using the currently officially valid methodology that yields, as the final result, an overall condition rating for the structure, accompanied with the list of partial ratings for separate structural parts. Data for all investigated structures are stored in a single database at the Roads Directorate of the Republic of Slovenia. On the level of individual structures, the details of each investigation are recorded in the Investigation Report. A total of 50.000 data were analysed.

\subsection{Data processing}

One of major deficiencies of the current condition assessment system, identified by scrutinizing current procedures, is the absence of a quality control/ assurance system that would be applied to the data acquired by inspection. Although the assessors are trained to detect, classify, and evaluate the observed damage in a unified manner, ad hoc trial comparative assessments carried out simultaneously on the same structure by several assessors showed, in some cases, significant discrepancies in recorded condition ratings. This occurrence, which leads to several inconsistencies in the collected data, was also studied by other researchers [11, 12]. The first shortcoming to take into account is related to the observation that the recorded overall condition rating of the structure sometimes increases significantly, and then decreases in the next assessment, although no renovation work was recorded in the database between assessments. This observation can be explained by the fact thata) the structure was repaired during the time interval under consideration

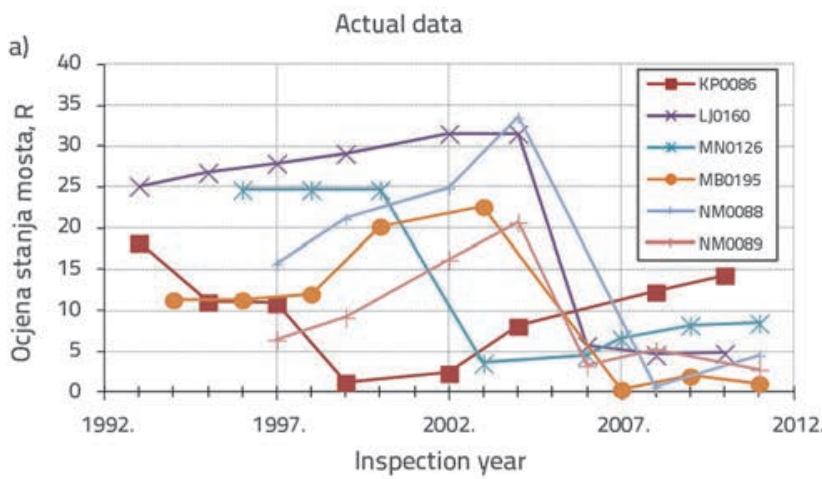

(and the repair was recorded in the Investigation Report but not in the database); or b) the ratings were not recorded appropriately (the most common reason for such erroneous recording is subjectivity and/or inadequate training of individual assessors, as discussed earlier). Consequently, the data for the ratings and their changes over time were scrutinized prior to the start of the analysis. The complete database and individual Investigation Reports were checked at that stage. For the data sets that exhibited inconsistent trends of ratings over time, the relevant individual Investigation Reports were also scrutinized. If repair activities were recorded in the Investigation Report, the data sets were kept and handled as described below.

Two partial data strings are distinguished for the bridges that were repaired during the time interval under consideration. The first one describes the behaviour of the structure prior to refurbishment, and the second one depicts changes of rating over time after refurbishment. Out of these two data strings, the longer partial data string (i.e. the one containing more data points) was taken into the account for further analysis, as depicted in Figure 1. The complete time interval was analysed for bridges that have not been repaired during the observed time interval.

In the next step, deterioration rates (defined as change in condition rating per time unit) for all structures and their parts (substructure, superstructure, and deck) were estimated using linear regression for the complete period under observation (attempts were also made to use the exponential regression curve; however the obtained results revealed that the linear relationship can represent well the available data, due to data variability [20]). For an individual structure $j$, the rating $y_{j, j i, ~}$ was determined as follows;

$y_{j, \text { lin }}=a+b \cdot x_{j}$

Where $b$ is an average deterioration rate for the interval under consideration, and $x_{j}$ represents time. Coefficients $a$ and $b$ were determined by applying the least square method [21] to the available datasets as follows;

$$
b=\frac{\sum_{j=1}^{p}\left(x_{j}-\bar{x}\right) \cdot\left(y_{j}-\bar{y}\right)}{\sum_{j=1}^{p}\left(x_{j}-\bar{x}\right)^{2}}
$$

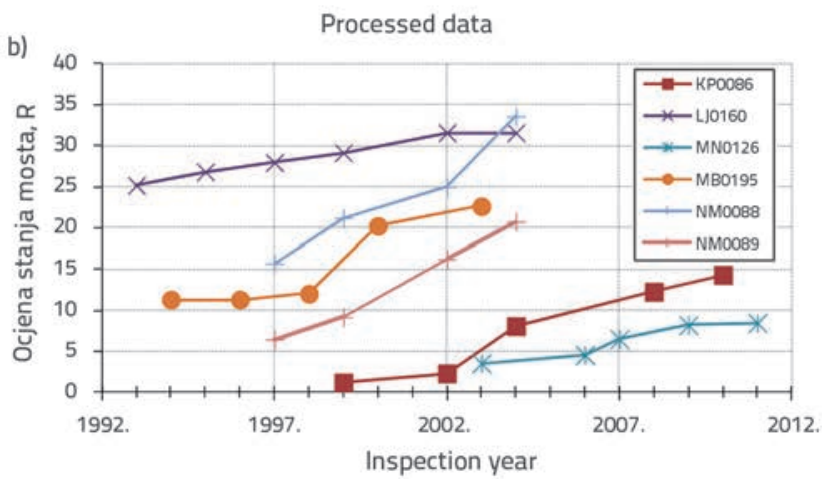

Figure 1. Condition rating changes with time (from 1993 to 2011) for 6 individual bridges, where inconsistency of recorded data due to rehabilitation is detected: a) actual inspection data; b) processed data (shorter data strings either before or after rehabilitation are removed from actual recorded data strings) 

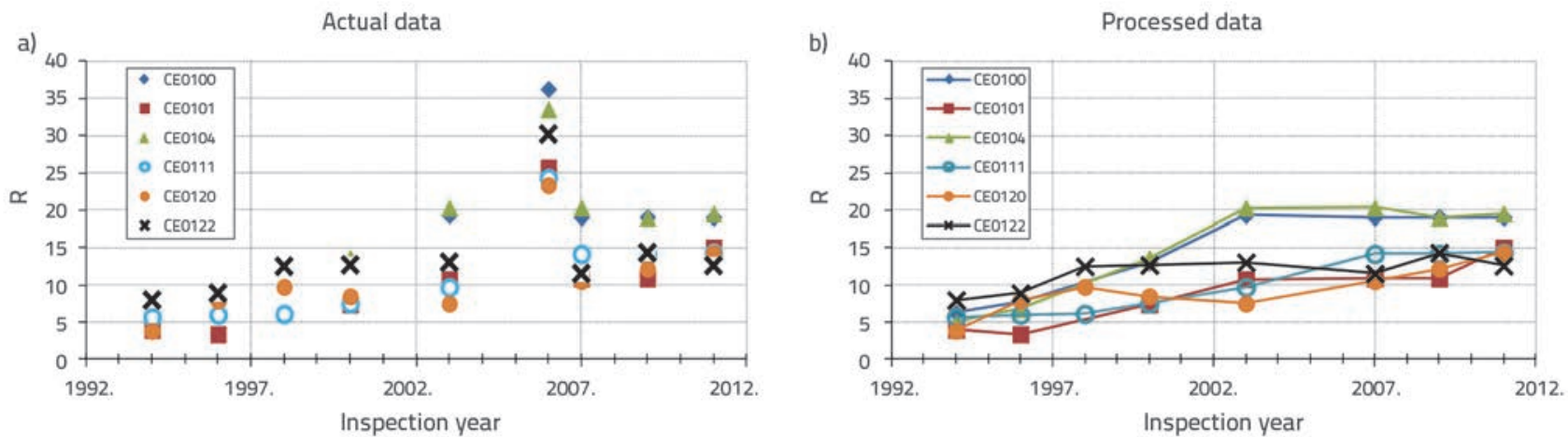

Figure 2. Condition rating changes with time for 6 individual bridges in the period from 1994 to 2011 for: a) Actual inspection data; b) Processed data (the rating value recorded in 2006 is removed due to its large inconsistency, which is judged to be a consequence of the inspector's unreliable judgment)

$a=\bar{y}-b \cdot \bar{x}$

$\bar{x}=\frac{1}{n} \cdot \sum_{j=1}^{p} x_{j}$

$\bar{y}=\frac{1}{n} \cdot \sum_{j=1}^{p} y_{j}$

$j$ indicates the year under consideration, $p$ is the final year of analysis, and $n$ is the dataset size.

The actual values of ratings in the year under consideration, $j$, differ from the values determined by the regression line, $y_{j \text { lin' }}$ that presents the course of deterioration. In order to determine the magnitude of discrepancy between the actual and the calculated rating values, the standard error of these two values was calculated. The calculation was carried out for entire structures and for their individual structural parts. The standard error, $\mathrm{SE}$, of the linear regression line defined by Eq. (10), $y_{j, \text { lin' }}$, was calculated as;

$S E=\sqrt{\frac{1}{(n-2)} \cdot\left[\sum_{j=1}^{p}\left(y_{j}-\bar{y}\right)^{2}-\frac{\left.\left[\sum_{j=1}^{p}\left(x_{j}-\bar{x}\right) \cdot\left(y_{j}-\bar{y}\right)\right]^{2}\right]}{\sum_{j=1}^{p}\left(x_{j}-x\right)^{2}}\right]}$

Where $\overline{\mathrm{x}}$ and $\overline{\mathrm{y}}$ are the mean values of the dataset, and $x_{j}$ and $y_{j}$ are the independent and dependent data, respectively.

The dataset is considered to be consistent if the standard error, $\mathrm{SE}$, conforms to the condition;

$\frac{\mathrm{SE}}{\bar{y}} \leq 0,3$

In Eq. 16 the criterion value (0.3) was selected on the basis of opinions given by several experts, experienced assessors in particular, who were asked to evaluate this value from the viewpoint of sufficient consistency of the datasets, and adequacy of the number of datasets available for further analysis. Therefore, if Eq. (16) is satisfied, then the data under consideration will be used for further analysis without change.

Conversely, if, for a given dataset, the standard error SEdoes not meet the criterion from Eq. (16), the data point for which the standard error is the largest is eliminated from the dataset, as it is considered to be unreliable. To ensure that a) there is no more than one extremely unreliable data point and b) the elimination of the selected data point results in significant (at least $30 \%$ ) reduction of the initial standard error, the following criterion needs to be met for the dataset after its processing;

$1,3 \cdot\left(S E_{1} / \bar{y}\right) \leq\left(S E_{0} / \bar{y}\right)$

where $S E_{1}$ is the standard error of the processed set (after the elimination of the data point with the largest standard error), and $S E_{0}$ is the standard error of the original data set.

If Eq. (17) cannot be satisfied for the dataset under consideration, the dataset as a whole is considered unreliable and is excluded from further examination. The analysis of complete data describing the condition of state road bridges shows that 2599 out of 4956 datasets (approx. $52 \%$ ) comply with the condition given in Eq. (16). After eliminating the single most unreliable data set in the string that did not meet the condition from Eq. (16), another $41 \%$ of the total datasets under consideration became suitable for further analysis. Out of the remaining datasets, $4 \%$ did not meet any of the conditions from Eqs. (16) and (17), and $3 \%$ contained data strings that are too short (with less than 3 data points) to be used in further analysis [20].

Results from the above-described procedure that ensures consistency of the data used in further analysis are presented in Figure 2 for a selection of 6 bridges. In 2006, the assessor assigned to these bridges extremely high rating values (Fig.2.a), which are clearly not in line with the trend exhibited by other ratings for these structures (recorded within the time interval under consideration). These extremely high rating values were eliminated from the dataset using the procedure defined by Eqs. (16) and (17). Standard errors of the processed datasets are significantly lower (up to $70 \%$ ) when compared to the values of the original datasets. Changes of condition rating over time for the processed datasets are depicted in Figure 2.b.

After processing the raw data, the average deterioration rate, $b$, was determined for all structures and their structural parts within the network, for all combinations of the parameters of influence (Table 2) by linear regression. Details of the procedure and the results are reported in [20].

\subsection{Determination of average deterioration rate}

The second goal of the study was to determine an average deterioration rate for structures and structural parts subjected 
to the selected combinations of parameters of influence. In order to analyse the bridge behaviour, condition rating ranges for bridge decks, substructures, and superstructures, were structured into 4 intervals defining deterioration levels (excellent, good, satisfactory, sufficient). The selected condition rating interval length for substructures / superstructures, and decks, is 3 and 2 rating units, respectively (Table 4 ).

The deterioration rate, $b$, is then calculated for each dataset, $k$ (defined for each individual condition rating interval) as;

$b_{k}=\frac{\sum_{j=1}^{p}\left(x_{k, j}-\overline{x_{k}}\right) \cdot\left(y_{k, j}-\bar{y}_{k}\right)}{\sum_{j=1}^{p}\left(x_{k, j}-\bar{x}_{k}\right)^{2}}$

For each combination of parameters of influence, the average deterioration rate $(\bar{b})$ is determined as;
$\bar{b}(M, C l, T, F, B e, R)=\frac{\sum_{k=1}^{r} b_{k}}{r}$

$r=r(M, C l, T, F, B e, R)$

Where $R$ denotes the condition rating level and $r$ the number of data sets with the same combination of parameters of influence within the condition rating interval.

The values of average deterioration rates $(\bar{b})$ for the structures under consideration were determined for all combinations of influence defined in Table 3. The values for reinforced concrete bridges located in the zone of continental climate are presented in Table 4

For the purpose of the analysis, the time required to achieve a pre-defined condition rating level is adopted as a dependent variable of the condition rating, and is defined by the piecewise linear relation. For the substructure and superstructure, the time

Table 4. Average deterioration rates for light (L), medium (M), and heavy (H) traffic load; bridges span across water

\begin{tabular}{|c|c|c|c|c|}
\hline \multicolumn{5}{|c|}{ a) reinforced concrete bridge decks } \\
\hline $\begin{array}{c}\text { Material } \\
\text { function type } \\
\text { structural } \\
\text { part }\end{array}$ & Traffic load & $\begin{array}{c}\text { Condition rating } \\
\text { Level (R) }\end{array}$ & $\begin{array}{c}\text { Number of } \\
\text { available } \\
\text { datasets, r }\end{array}$ & $\begin{array}{c}\text { Deterioration } \\
\text { rate }(\bar{b}) \\
\left.\text { [year }{ }^{-1}\right]\end{array}$ \\
\hline \multirow{12}{*}{ 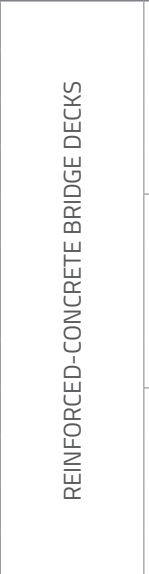 } & \multirow{4}{*}{ L } & {$[0 \sim 2)$} & 144 & 0,09 \\
\hline & & {$[2 \sim 4)$} & 158 & 0,22 \\
\hline & & {$[4 \sim 6)$} & 67 & 0,32 \\
\hline & & [6 8] & 32 & 0,50 \\
\hline & \multirow{4}{*}{ M } & {$[0 \sim 2)$} & 59 & 0,12 \\
\hline & & {$[2 \sim 4)$} & 70 & 0,21 \\
\hline & & {$[4 \sim 6)$} & 28 & 0,32 \\
\hline & & [6 8] & 14 & 0,45 \\
\hline & \multirow{4}{*}{$\mathrm{H}$} & {$[0 \sim 2)$} & 48 & 0,09 \\
\hline & & {$[2 \sim 4)$} & 54 & 0,22 \\
\hline & & {$[4 \sim 6)$} & 18 & 0,26 \\
\hline & & [6 8] & 12 & 0,45 \\
\hline
\end{tabular}

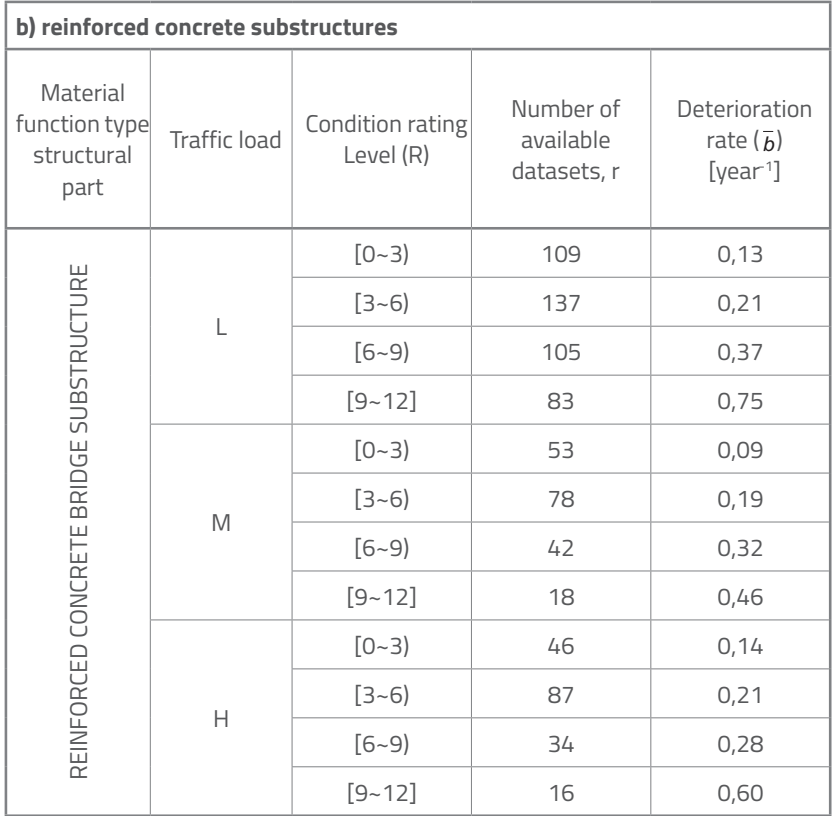

\begin{tabular}{|c|c|c|c|c|}
\hline \multicolumn{5}{|c|}{ c) reinforced concrete superstructures } \\
\hline$\ddot{\widetilde{\Sigma}}$ & \multirow{4}{*}{ L } & {$[0 \sim 3)$} & 163 & 0,11 \\
\hline$\underline{E}$ & & {$[3 \sim 6)$} & 104 & 0,28 \\
\hline 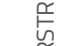 & & [6 9) & 55 & 0,48 \\
\hline 突 & & [9 12] & 65 & 0,84 \\
\hline $\begin{array}{l}\vec{n} \\
\text { 峲 }\end{array}$ & \multirow{4}{*}{$M$} & {$[0 \sim 3)$} & 72 & 0,08 \\
\hline$\frac{\mathrm{Q}}{\bar{x}}$ & & {$[3 \sim 6)$} & 39 & 0,25 \\
\hline \multirow{6}{*}{ 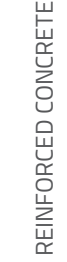 } & & [6 9) & 29 & 0,33 \\
\hline & & [9 12] & 24 & 0,79 \\
\hline & \multirow{4}{*}{$\mathrm{H}$} & {$[0 \sim 3)$} & 54 & 0,12 \\
\hline & & {$[3 \sim 6)$} & 34 & 0,21 \\
\hline & & [6 9) & 26 & 0,31 \\
\hline & & [9 12] & 17 & 0,67 \\
\hline
\end{tabular}

\begin{tabular}{|c|c|c|c|c|}
\hline \multicolumn{5}{|c|}{ d) reinforced concrete bridges located in continental climate zone } \\
\hline \multirow{12}{*}{ 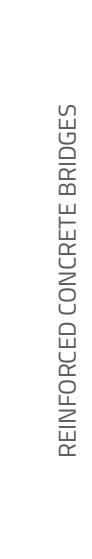 } & \multirow{4}{*}{ L } & [0 5] & 56 & 0,33 \\
\hline & & [5 10] & 72 & 0,48 \\
\hline & & [10 15] & 92 & 0,65 \\
\hline & & [15 20] & 182 & 1,18 \\
\hline & \multirow{4}{*}{ M } & [0 5] & 27 & 0,29 \\
\hline & & [5 10] & 40 & 0,47 \\
\hline & & {$[10 \sim 15)$} & 38 & 0,62 \\
\hline & & [15 20] & 66 & 1,04 \\
\hline & \multirow{4}{*}{$\mathrm{H}$} & [0 5] & 9 & 0,31 \\
\hline & & [5 10] & 43 & 0,57 \\
\hline & & [10 15] & 34 & 0,58 \\
\hline & & [15 20] & 49 & 0,92 \\
\hline
\end{tabular}


is determined by Eq. (21). The value of time for bridge deck, and for bridge as a whole, is determined with expressions similar to Eq. (21), where the condition rating interval size is taken to be 2 and 5 units, respectively.

$$
t(R)=\left\{\begin{array}{l}
\frac{R}{\overline{\bar{b}}_{[0,3)}} ; R \in[0,3) \\
\frac{3}{\overline{\bar{b}}_{[0,3)}}+\frac{R-3}{\bar{b}_{[3,6)}} ; R \in[3,6) \\
\frac{3}{\bar{b}_{[0,3)}}+\frac{3}{\bar{b}_{[3,6)}}+\frac{R-6}{\bar{b}_{[6,9)} ; R \in[6,9)} \\
\frac{3}{\bar{b}_{[0,3)}}+\frac{3}{\bar{b}_{[3,6)}}+\frac{3}{\bar{b}_{[6,9)}}+\frac{R-9}{\bar{b}_{[9,12]}} ; R \in[9,12]
\end{array}\right\}
$$

\subsection{Dependence of deterioration rate on parameters of influence}

\subsubsection{Traffic load}

The influence of traffic load on deterioration rate of structures under consideration was analysed for bridges made of all structural materials. Results were obtained for the whole bridge and for the bridge deck alone.

As very few structures are subjected to medium or heavy traffic load in the Alpine climate region, the traffic load influence was analysed for the continental and Mediterranean climate regions only. It can be observed that the structures subjected to heavy traffic load deteriorate at practically the same rate as those subjected to medium/light traffic load, when the structures are located in the same climate region [20]. The only minor discrepancy from the observed rating trend can be noticed for the structures subjected to medium traffic load that are located in the Mediterranean climate region.

The influence of traffic load on the behaviour of structures was also analysed for individual structural parts, out of which bridge decks are the most exposed segments. Results (Table 4) show that the deterioration of structures and their structural parts does not depend on traffic load. The data analysis for stone bridges, prestressed bridges and steel bridges yield results that are similar to those obtained for reinforced concrete structures. Taking into account the scatter of recorded condition rating values, we can conclude, on the basis of the results presented in Table 4, that the deterioration rate for structures taken as a whole, and for their structural parts, does not depend on the traffic load. We attribute this behaviour to the fact that the structures under consideration were designed and constructed according to national structural codes requiring structures to be mechanically resistant to appropriate design traffic and other loads. Furthermore, the exhibited behaviour can also be attributed to the use of appropriate, properly designed materials both in pavement and in other structural parts of the bridge.

As a consequence, other parameters of influence are analysed without taking into account the traffic load.

\subsubsection{Climate type}

In Slovenia, only the reinforced concrete structures are present in all three climate zones. Steel and stone bridges are located in continental and Mediterranean climate zones, and prestressed bridges can be found exclusively in areas with continental climate. The influence of climate type on overall deterioration of bridges, and on deterioration of their separate structural parts, was studied in the initial part of the analysis. The analysis of available data [20] shows that the climate type influences deterioration of the substructure, superstructure and bridge deck (Fig. 3). Condition rating changes were also analysed for road equipment. The road equipment consists of protective barriers for sidewalks, road barriers, railings, lighting, infrastructure channels/ducts, and expansion joints. With the exception of expansion joints, the analysis of data shows that the deterioration of these elements does not depend on climate type [20]. As a consequence, the road equipment was not considered for further analysis.

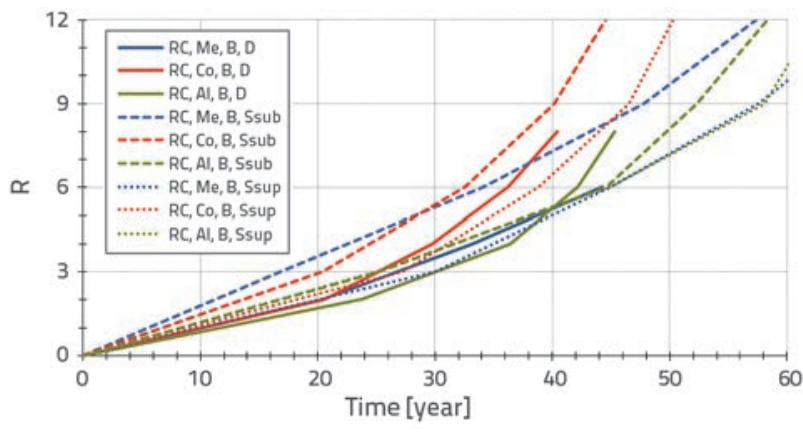

Figure 3. Temporal deterioration development (expressed as time required to achieve pre-defined level of $R$ ) for reinforced concrete bridge structural parts, as a function of climate type

\subsubsection{Structural material and structural type}

The deterioration rate of structures was studied with respect to the type of structural material. For the inventory under consideration, four different structural materials are encountered in the superstructure. The substructure is however constructed of reinforced concrete regardless of the type of the superstructure, except for stone bridges that represent a minor portion of the inventory. Consequently, substructure deterioration rates were determined for reinforced concrete and stone substructures only. Typical examples of substructures and superstructures are presented in Figure 4. Elements of bridge decks are selected exclusively according to the needs of the expected traffic, and are not related to structural material of the bridge. Therefore, their deterioration is expected to be independent of the deterioration affecting structural materials of the bridge.

Examples of rating changes over time (required to achieve a predefined condition rating level, as defined by Eq. (21)) are presented in Figures 5 and 6 for bridge decks, substructures, and superstructures encountered in the continental climate zone. 

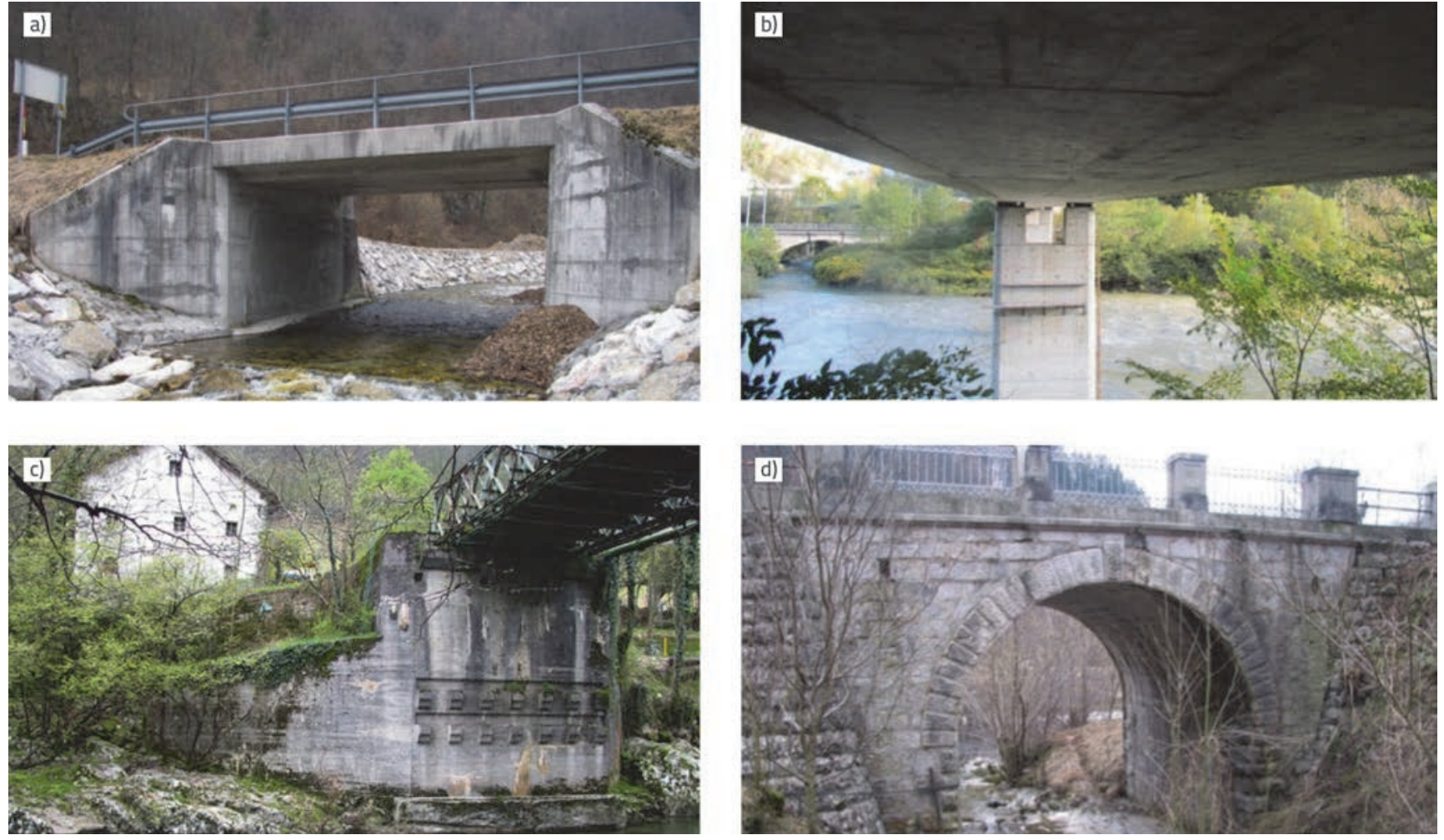

Figure 4. Examples of bridge substructures with superstructure made of: a) reinforced concrete; b) pre-stressed concrete; c) steel; d) stone. The substructure a), b), and c) is made of concrete and d) of stone

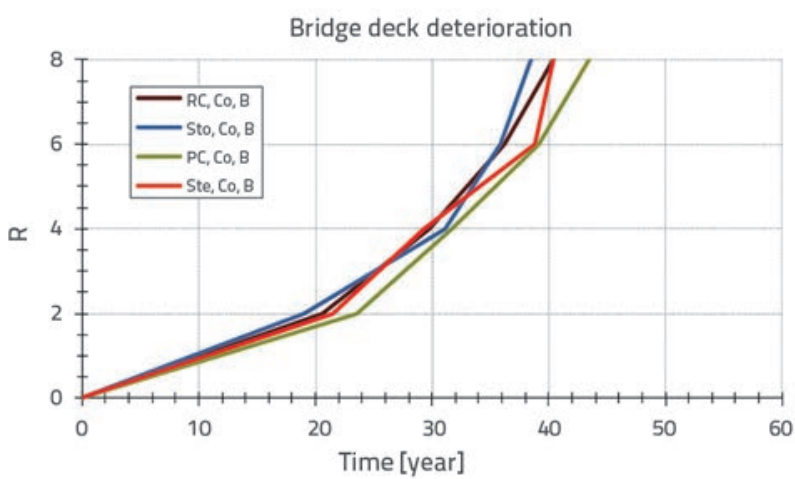

Figure 5. Development of deterioration over time (expressed as time required to achieve the pre-defined level of $R$ ) for bridge decks as a function of structural material of bridges spanning bodies of water (continental climate)

Due to established practical conventions, time is depicted on $x$ axis and condition rating on y axis. Results presented in Figure 5 show almost identical bridge deck deterioration rates regardless of structural material of the bridge, for continental climate. Similar results were obtained for bridge decks in other climate zones [20]. Differences between bridge deck deterioration rates for bridges constructed of different materials were observed at high degradation levels only [20].

The analysis of influence of structural type on the observed deterioration rates of the bridges under consideration was carried out in the next step. Bridges across water in Slovenia are constructed

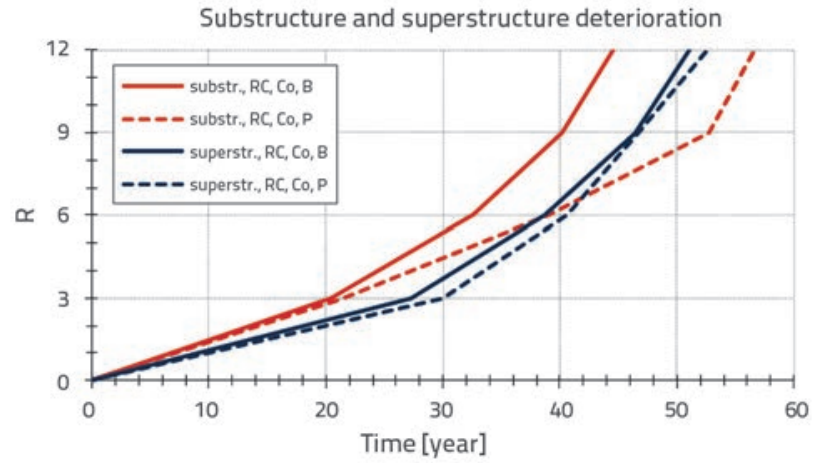

Figure 6. Development of deterioration over time (expressed as time required to achieve the pre-defined level of $R$ ) for substructures and superstructures of reinforced concrete bridges as a function of structural type (continental climate)

of all structural materials and their combinations. On the other hand, bridges spanning valleys or roads are built of reinforced concrete only (Table 3). The majority of such structures are located in the continental and Mediterranean climate zones while only 11 are located in the Alpine climate zone. The relationship between the structural type and exhibited deterioration rate of the structures was therefore determined only for reinforced-concrete structures located in the Mediterranean and continental climate zones.

The analysis of data shows that substructures of the bridges spanning valleys or roads deteriorate at a visibly lower rate (approximately $25 \%$ ) than the substructures of bridges spanning 


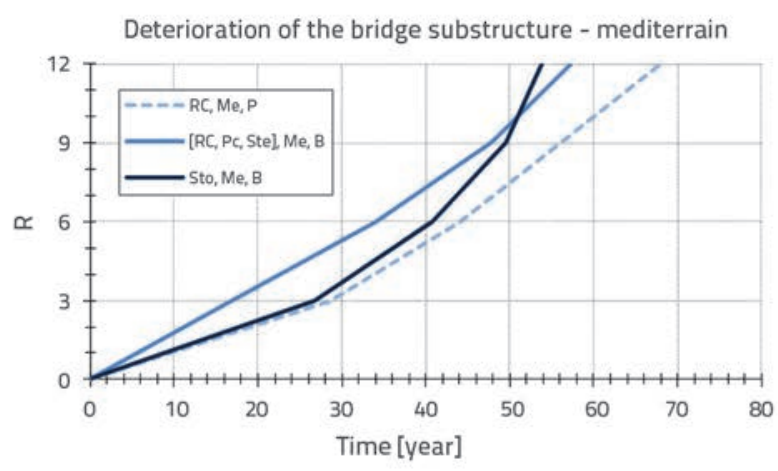

Deterioration of the bridge substructure - continental

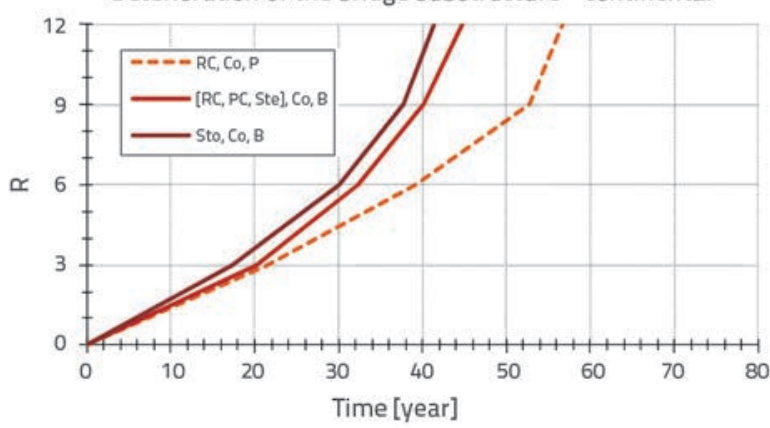

Deterioration of the bridge substructure - alpine

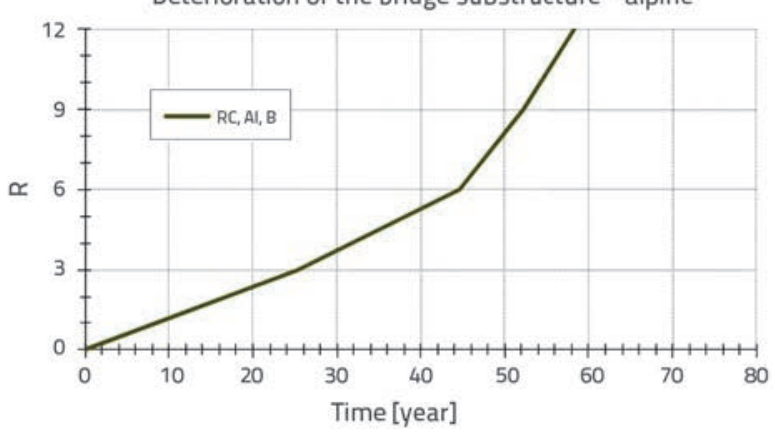

Bridge deck

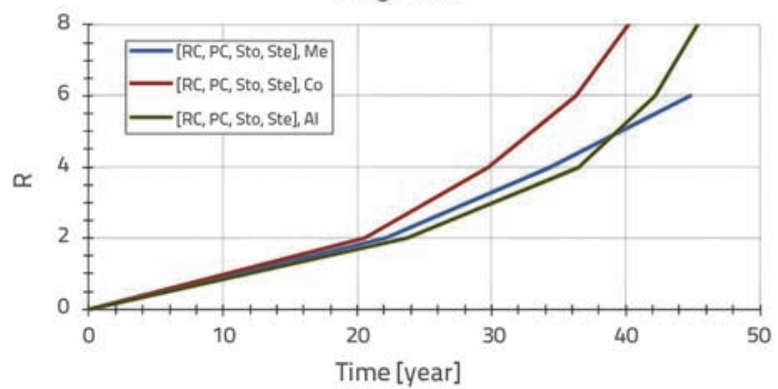

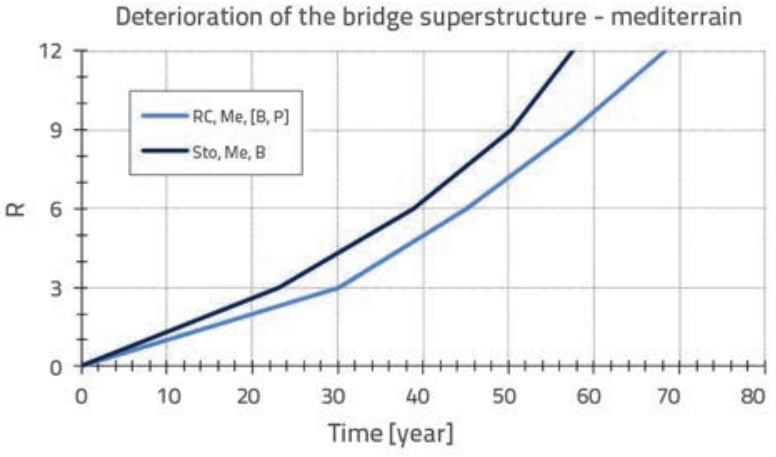

Deterioration of the bridge superstructure - continental

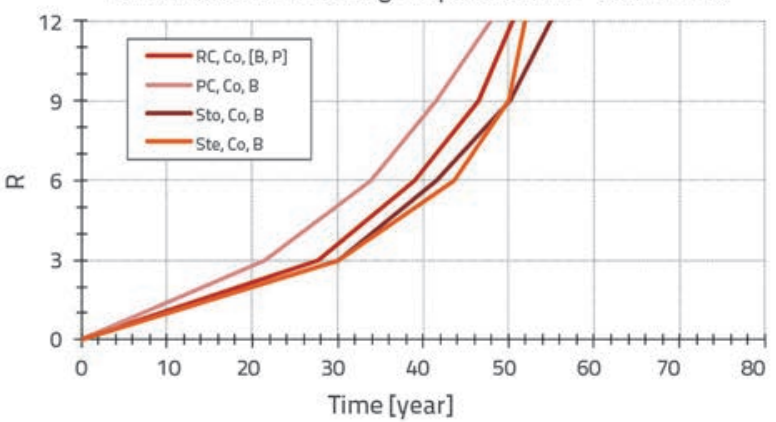

Deterioration of the bridge superstructure - alpine

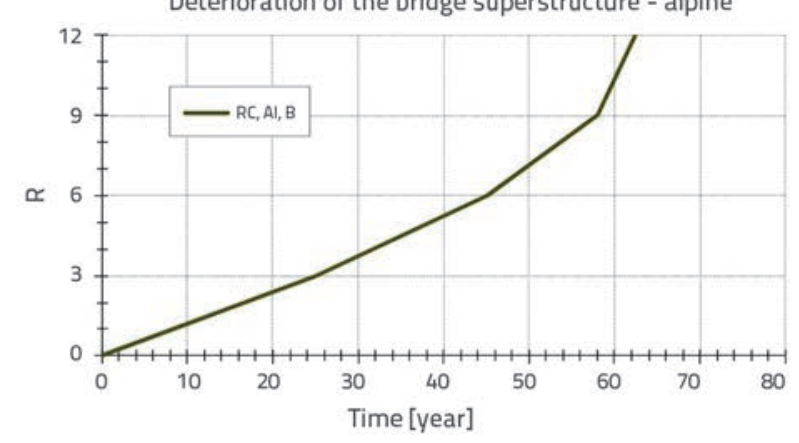

Figure 7. Deterioration development (expressed as time required to achieve the pre-defined level of R) for structural parts of bridges, for the considered climate types, structural materials, and structure types

bodies of water. As already discussed, this observation can be explained by permanent exposure of structural elements to river water that can be further aggravated by floods or water level changes with or without simultaneous occurrence of sub-zero temperatures. Furthermore, it can be observed that superstructures of bridges spanning bodies of water and valleys/ roads deteriorate at almost the same rate. The behaviour of substructures and superstructures for reinforced concrete bridges over water, located in continental climate, is presented in Figure 6. 


\section{Results and discussion}

The relationships between parameters of influence and bridge deterioration rate were determined based on the analyses carried out for the available bridge rating data. The corresponding results are presented in Figure 7. It can be observed that climate exerts the greatest impact on the bridge deterioration rate (for all considered parameters of influence). The progress of decay at all structural parts of bridges is the slowest in the Mediterranean climate, while it is significantly faster in the continental climate (where a large number of freeze/thaw cycles occurs during winter). The deterioration of structural parts in the Alpine climate is almost as slow as in the Mediterranean climate, which is most likely due to a small number of annual freeze-thaw cycles, as temperatures in winter months are constantly below the freezing point. The deterioration process in the Alpine climate was analysed for reinforced concrete structures only, as the number of other bridge types is very small. Since even the number of reinforced concrete structures in Alpine climate zone is relatively small (when compared to the number of these structures in other climate zones), the results obtained for these structures may be associated with a higher level of uncertainty as well.

The structural type, as already stated, affects only the rate of deterioration of substructure elements. This parameter of influence can only be analysed for reinforced concrete, as there are no stone bridges over valleys or roads on Slovenian state roads. Exposure to running water can cause soil erosion at or below foundations, and abrasion to wing walls and abutments. During floods, mechanical damage can occur due to large pieces of material floating in the stream at high speeds. These events can not occur under bridges spanning valleys or roads, which makes their substructure deterioration slower compared to that of bridges spanning rivers, as can clearly be seen in Figure 7.

It can also be concluded from Figure 7 that the influence of material type on the progress of deterioration is relatively small. Furthermore, the data analysis shows that the deterioration of substructures and superstructures is almost independent of the structural material used. Visible differences in deterioration rates when various structural materials are used can be noticed only when the structure is already considerably damaged. An accelerated deterioration of steel structures in later years is attributed to the fast progress of corrosion, when steel elements are no longer adequately protected by the anti-corrosion coating. According to field experience, stone bridges begin to deteriorate faster after failure of the first stone block, as the appearance of the first gap between blocks in the structural stone element typically results in progression of damage and accelerated loss of material.

The traffic load analysis (as discussed in Section 3.3.1) shows that there is no correlation between the bridge elements deterioration rate and the magnitude of traffic load. This observation can be explained by appropriate design of structures in relation to the expected traffic load, but could also be the result of over sizing of structural elements during design.
The presented methodology consists of two main components: field inspection and calculation of condition ratings. As already acknowledged [11], the visual field inspection has several deficiencies such as the subjective observation of the extent and intensity of damage recorded by the assessors and, in some cases, their lack of expertise. The result of these deficiencies is a relatively large dispersion of condition rating values in individual data sets.

Several authors who addressed similar topics, e.g. $[1,7,11,12]$ emphasized that field inspections would yield higher quality data if assessors a) had regular training, b) used uniform procedures for the implementation of inspections, and c) periodically compared results to unify condition rating values for the same extents and intensities of damage. To validate the reliability of results, occasional special inspections should be introduced as an additional quality control measure.

The current condition rating methodology has two major weaknesses. The length and/or surface area of bridges is not accounted for when determining the extent of damage to bridges. Furthermore, the assessment methodology does not identify and take into account possible concentration of damage and deficiencies in a relatively small area that may constitute a considerable risk to the load carrying capacity and durability of structures. The fact that expansion joints are classified as equipment (and not as a structural part) disguises the importance and influence of this element on the overall behaviour of the structure.

To remedy these shortcomings, a new method of assessment is being developed, but has not as yet been sufficiently tested. As a vast majority of bridges on Slovenian state roads have relatively short spans and are a part of the two-lane road system, the shortcomings of the currently used methodology do not significantly affect final results of the presented analysis. However, with the completion of the Slovenian highway network, which contains a large number of longer and wider bridges, the establishment of a new condition assessment methodology will become necessary.

Due to continuously increasing truck weight, and environmental influences that adversely affect the condition of road structures, it can be anticipated that the importance of an adequate condition rating methodology will be even more pronounced in the future than it is today.

\section{Conclusions}

The paper presents main characteristics of the state road bridge inventory in Slovenia, and the methodology used for rating condition of bridges. Parameters characterizing the inventory under consideration are identified and the results of bridge inspections carried out over the last 20 years are analysed.

Results obtained by analysis of the existing data show that the condition of bridges is dominantly influenced by two parameters: climate and exposure to water. To provide for the safety and usability of state roads, structures situated in harshclimate zones should be monitored more frequently in order to 
detect potential decline in performance. The results obtained also show that the current assessment methodology needs to be updated, particularly in elements related to the description and assessment of the local concentration of damage. Data collection should be computer-supported so that a greater efficiency can be achieved.

Future research should include restructuring of the existing database, so that the deterioration of bridges on roads where deicing salts are used in the winter can be studied in more detail. From the viewpoint of road managers, further research is also required in the field of decision support systems focused on the bridge maintenance, repair, and renovation activities. Such tools provide a rational basis for the determination of structures that should be given priority in the maintenance, repair and renovation works, and will consequently be of assistance to system managers in the decision-making processes.

\section{Acknowledgements}

The authors extend their thanks to the Slovenian Roads Agency for providing them with access to the national state road network database, and to Prof. Antonio C.M. Sousa for the review of the text. The comments of anonymous reviewers that led to improvement of the paper are appreciated. Financial support received from the University of Ljubljana through the Doctoral Studies Scheme for Promoting Cooperation with the Industry, and from the Slovenian Research Agency through the Research Programme No P2-0185, is gratefully acknowledged.

\section{LITERATURA}

[1] Hearn, G.: Bridge Inspection practices. National cooperative highway research program - NCHRP. Synthesis 375, 2007, http://onlinepubs.trb.org/onlinepubs/nchrp/nchrp_syn_375.pdf, 8.6.2014.

[2] Šelih, J., Kne, A., Srdič, A., Žura, M.: Multiple-criteria decision support system in highway infrastructure management. Transport, Vol. 23, pp. 299-305, 2008.

[3] Frangopol, D.M.: Life-cycle performance, management, and optimisation of structural systems under uncertainty: accomplishments and challenges. Structure and infrastructure engineering: Maintenance, Management, Life-Cycle Design and Performance, Vol. 7, pp. 389-413, 2011, http://dx.doi. org/10.1080/15732471003594427, 8.6.2014.

[4] Ellingwood, B.R.: Risk-benefit-based design decisions for lowprobability/high consequence earthquake events in mid-America. Progress in Structural Engineering and Materials, Vol. 7, pp. 5670, 2005.

[5] Testa, R.B., Yanev, B.S.: Bridge maintenance level assessment. Computer-Aided Civil and Infrastructure Engineering. Vol. 17, pp. 358-367, 2002.

[6] Yanev, B., Richards, G.: Designing Bridge Maintenance on the Network and Project Levels. Structure and Infrastructure Engineering. Vol. 9, pp. 349-363, 2013.

[7] Woodward, R.J., Cullington, D.W., Daly, A.F., Vassie, P.R., Haardt, P., Kashner, R., Astudillo, R., Velando, C., Godart, B., Cremona, C. Mahut, B., Raharinaivo, A., Lau Markey, I., Bevc, L., Peruš, l.: Bridge management systems: Extended review of existing systems and outline framework for a European system. BRIME PL97-2220, 227 p., 2001.

[8] Morcous, G.: Comparing the use of artificial neural networks and case based reasoning in modeling bridge deterioration. Annual conf. of the Canadian society of civil engineering, Montreal, 2002.

[9] Žnidarič, J., Terčelj, S., Marolt, J.: Določite v standardov uporabnosti cestnih mostov - številčna ocean stanja mostov - rating. Ljubljana. Zavod za raziskavo materiala in konstrukcij ZRMK, 50 p, 1990 (In Slovenian)

[10] Žnidarič, J., Bevc, L., Capuder, F., Marolt, J., Srpčič, J., Terčelj, S., Žnidarič, A., Vojska, J.: Vrednotenje varnosti cestnih mostov (Inženirske osnove za računalniško obdelavo poročil o pregledu mostov). Ljubljana. Zavod za raziskavo materiala in konstrukcij ZRMK, 43 p, 1992 (In Slovenian).

[11] Tenžera, D., Puž, G., Radić, J.: Visual inspection in evaluation of bridge condition, GRAĐEVINAR 64 (2012) 9, pp. 717-726.

[12] Gattulli, V., Chiaramonte, L.: Condition Assessment by visual inspection for a Bridge Management System, Computer-Aided Civil and Infrastructure Engineering, Vol. 20, pp. 95-107, 2005.

[13] Revizijsko poročilo - vzdrževanje avtocest (Revision report maintenance of roads). 2010. Izrekmnenja o vzdrževanju avtocest v obdobju 2005 - 2007. Računsko sodišče RS, http://www.rs-rs. si/rsrs/rsrs.nsf/l/K29468874F0E38504C12574C6003CCF53? openDocument\&appSource=AA288C363EA722B2C125715C00 1B5795, 8.6.2014 (In Slovenian)

[14] Regulation on Roads, Official Gazette of Republic of Slovenia, No.109/2010, http://www.uradni-list.si/1/objava.jsp?urlid=2010 109\&stevilka=5732, 8.6.2014.

[15] Žarnić, R.: Lastnostigradiv. Univerza v Ljubljani, Fakulteta za gradbeništvo in geodezijo, 350 p., 2005 (In Slovenian).

[16] Moncmanova, A.: Environmental deterioration of materials, WIT Press, Southampton, UK, 312 p., 2007.

[17] TSC06.511: http://www.dc.gov.si/fileadmin/dc.gov.si/ pageuploads/pdf_datoteke/TSC/TSC-06-511-2009.pdf, 8.6.2014.

[18] Sistonen, E., Vesikari, E.: Effect of interacted deterioration parameters in service life of concrete structures in cold environments - state of the art, Research Report VTT-R-09217-08, VTT, 2008, http://www.vtt.fi/files/ sites/ duraint/task_1_state_of_the_art.pdf, 8.6.2014.

[19] Direkcija za ceste, http://www.dc.gov.si/, 8.6.2014.

[20] Kušar, M.: Condition assessment of state road network bridges, Internal report, University of Ljubljana, 2013 (In Slovenian).

[21] Turk, G.: Verjetnostni račun in statistika. 1.izd. Ljubljana: Fakulteta za gradbeništvo in geodezijo, 2012. 264 pp. (In Slovenian) 